\title{
FOLKLOR DALAM TRADISI NUJUH BULANAN DI KECAMATAN CILAWU KABUPATEN GARUT UNTUK BAHAN PEMBELAJARAN MEMBACA ARTIKEL BUDAYA DI SMA
}

\author{
Neneng Jeni T \\ MGMP Bahasa Sunda Kabupaten Garut \\ Pos-el: inu_zen93@yahoo.com
}

\begin{abstract}
Abstrak
Penelitian ini dilatarbelakangi oleh kurangnya pengetahuan masyarakat terhadap tradisi nujuh bulanan. Masyarakat sudah tidak terlalu mementingkan tradisi nujuh bulanan, padahal tradisi ini merupakan warisan dari nenek moyang kita yang dapat menjadi ciri khas orang Sunda. Penelitian ini untuk mendeskripsikan: 1) tatacara pelaksanaan tradisi nujuh bulanan, 2) folklor apa saja yang terdapat dalam tradisi nujuh bulanan, 3) hasil penelitian untuk bahan pembelajaran membaca artikel budaya di SMA. Metode yang digunakan dalam penelitian ini adalah deskriptif kualitatif, dengan menggunakan tehnik observasi, wawancara dan dokumentasi.Instrumen yang digunakan dalam penelitian ini adalah kamera dan pedoman wawancara. Hasilnya adalah: pertama, bahwa dalam pelaksanaan tradisi nujuh bulanan terdapat tiga hal yang biasa dilakukan, diantaranya pengajian, membuat rujak dan memandikan yang sedang mengandung. Kedua, dalam tradisi nujuh bulanan terdapat folklor lisan, folklor setengah lisan dan folklor non lisan. Ketiga, hasil penelitian ini dapat digunakan sebagai bahan pembelajaran membaca artikel budaya di SMA kelas XII.Kesimpulan penelitian ini adalah agar masyarakat lebih mengenal tradisi-tradisi leluhur kita kemudian dapat menjaga dan melestarikannya.Saran ditujukan kepada peneliti selanjutnya agar lebih mencari dan menggali lebih dalam tentang mengenai tradisi masyarakat Sunda.
\end{abstract}

Kata Kunci: folklor, tradisi nujuh bulanan, pembelajaran membaca

\section{FOLKLORE ON TINGKEBAN TRADITION IN CILAWU SUB-DISTRIC OF GARUT IN TEACHING READING CULTURE ARTICLE FOR GRADE SENIOR HIGH SCHOOL}

\begin{abstract}
This study is based on the lack of people knowledge about tingkeban tradition. People have not been prioritizing tingkeban tradition lately, meanwhile this tradition is a heritage from the descent which can be defined as a thew for Sundanese. The aims of this study are to describe: 1) procedure of tingkeban tradition, 2) folklore on tingkeban tradition, 3) the finding of this study as teaching material for reading culture article at senior high school. This study uses desctiptive qualitative method by using technic observation, interview and documentation. Instrument that is used in this study is a camera and a handbook of interview. The finding shows that: first, in the implementation of tingkeban tradition there are three steps that should be done, those are reading holly Qur'an, making traditional fruits and vegetables salad dish (rujak) and bathing pregnancy woman. Second, there are three kinds of folklore in tingkeban tradition, those are oral folklore, half-oral folklore, and verbal folklore. Third, the finding of this study can be used as teaching material for reading culture article on 12th grade of senior high school. The result of this study is expected to people especially Sundanese in order to know more about their traditions so
\end{abstract}


that it can be maintained and preserved. A recommendation is aimed for the next researcher to analyze and to have deeper exploration about Sundanese tradition.

Key word: folklore, tingkeban tradition, teaching reading

\section{PENDAHULUAN}

Nujuh bulanan merupakan salah satu kebiasaan yang masih sering dilakukan oleh masyarakat Kecamatan Cilawu. Kecamatan ini berada di wilayah Kabupaten Garut.

Selamatan nujuh bulanan merupakan salah satu adat- istiadat Sunda yang masih suka dilakukan ketika ada salah seorang wanita yang sedang mengandung dan umur kandungannya menginjak tujuh bulan. Biasanya selamatan nujuh bulanan dilaksanakan oleh perempuan yang mengandung anak pertama. Dalam menentukan selamatan nujuh bulanan, orang tua dulu biasanya menghitung tanggal yang ada angka tujuhnya.

Menurut Mustapa (1996, hlm. 16) ketika ada seorang wanita yang sedang mengandung, dan umur kandunganya menginjak umur tujuh bulan, keluarga harus sudah siap-siap mengadakan selametan tingkeban. Salametan tingkeban merupakan upacara adat atau tradisi di Pasundan ketika umur kandungan menginjak umur tujuh bulan.

Nujuh bulanan atau tingkeban merupakan salah satu tradisi masyarakat Sunda. Dalam masyarakat Jawa pun terdapat tradisi nujuh bulanan, tradisi ini disebut upacara mitoni. Asal katanya dari kata 'am' (awalan am menunjukan kata kerja), dan 'pitu' yang berarti angka tujuh. Upacara mitoni merupakan suatu adat kebiasaan yang dilaksanakan ketika umur kandungan menginjak umur tujuh bulan, dan merupakan kehamilan yang pertama serta mempunyai tujuan agar bayi yang sedang dikandungnya berada dalam keselamatan. (Chandrarini,2010).

Dalam selamatan nujuh bulanan, ada tradisi-tradisi yang biasa dilakukan. Tradisi menurut Koentjaraningrat (dalam Yuniawati, 2012, hlm 24) merupakan satu kegiatan yang mewah dan ramai tetapi keramat dan dilakukan secara hikmat.

Tradisi nujuh bulanan dapat dikaji oleh kajian folklor. Folklor merupakan bagian dari kebudayaan yang diwariskan secara turun-temurun dari satu generasi yang lebih tua ke generasi seterusnya melalui lisan (Danandjaja, 2007, hlm. 3). Tradisi nujuh bulanan dianggap memiliki berbagai bentuk folklor, seperti folklor lisan, folklor sebagian lisan, dan folklor non lisan. Dari folklor tersebut, kita dapat mengetahui pesan-pesan moral yang terdapat didalamnya yang mungkin berguna bagi kehidupan kita.

Pada saat ini, tradisi nujuh bulanan sudah jarang dilaksanakan disebabkan masyarakat sudah tidak terlalu mementingkan tradisi ini. padahal tradisi ini dapat dijadikan identitas orang Sunda. Oleh sebab itu, kita sebagai orang sunda harus memelihara dan menjaga hal-hal yang diwariskan oleh nenek moyang kita karena pasti mempunyai manfaat bagi kehidupan kita. Salah satu caranya memeliharanya yaitu dengan cara memasukan materi kebudayaan ke dalam pembelajaran di sekolah agar siswa-siswa sebagai generasi penerus mengetahui tradisi leluhurnya.

Tujuan penelitian ini untuk mendeskripsikan;

1) Tata cara pelaksanaan dalam tradisi nujuh bulanan;

2) Folklor apa saja yang terdapat dalam tradisi nujuh bulanan;

3) Alternatif untuk bahan pembelajaran membaca artikel kebudayaan di SMA kelas XII.

\section{METODE}

Metode penelitian yang dipakai dalam penelitian ini adalah metode penelitian deskriptif kualitatif. 
Menurut Arikunto (2010, hlm. 3) memaparkan bahwa istilah deskriptif berasal dari istilah bahasa inggris describe yang berarti memaparkan atau menggambarkan sesuatu hal, misalnya keadaan, kondisi, situasi, peristiwa, kegiatan, dan lain-lain. Dalam penelitian ini, metode penelitian deskritif kualitatif mempunyai tujuan untuk mendeskripsikan tata cara pelaksanaan dalam tradisi nujuh bulanan, folklor yang terdapat dalam tradisi nujuh bulanan serta alternatif untuk bahan pembelajaran membaca artikel kebudayaan di SMA kelas XII.

Dalam penelitian ini terdapat empat langkah, yaitu persiapan, mengumpulkan data, mengolah data, dan menyusun laporan. Tehnik yang digunakan dalam penelitian ini yaitu tehnik observasi, tehnik wawancara, dan tehnik observasi. Instrumen yang dipakai dalam penelitian ini yaitu kamera digital dan pedoman wawancara.

Sumber data yang dipakai dalam penelitian ini meliputi;

1) Paraji yang biasa memimpin dalam selametan nujuh bulanan.

2) Rekaman dari prosesi selametan nujuh bulanan.

\section{HASIL DAN PEMBAHASAN}

Berdasarkan hasil penelitian, dalam tradisi nujuh bulanan terdapat tiga kegiatan pokok yang biasa dilakukan, yaitu pengajian, membuat rujak, dan memandikan yang sedang mengandung.

Pengajian dilaksanakan malam sebelum besoknya memandikan yang sedang mengandung. Dalam pengajian biasanya disediakan syarat-syarat, di antaranya kain samping tujuh, kelapa muda (dawegan), sesajen, cobek, kipas bambu atau hihid, lentera, benang putih serta jarum, hahampangan, dodol dan wajit ngora, dan air kembang. Pengajian biasanya dipimpin oleh seorang ustad, biasanya membacakan surat Mariyam, Surat Yusuf, Surat Yasin, serta Solawat Kamilah.
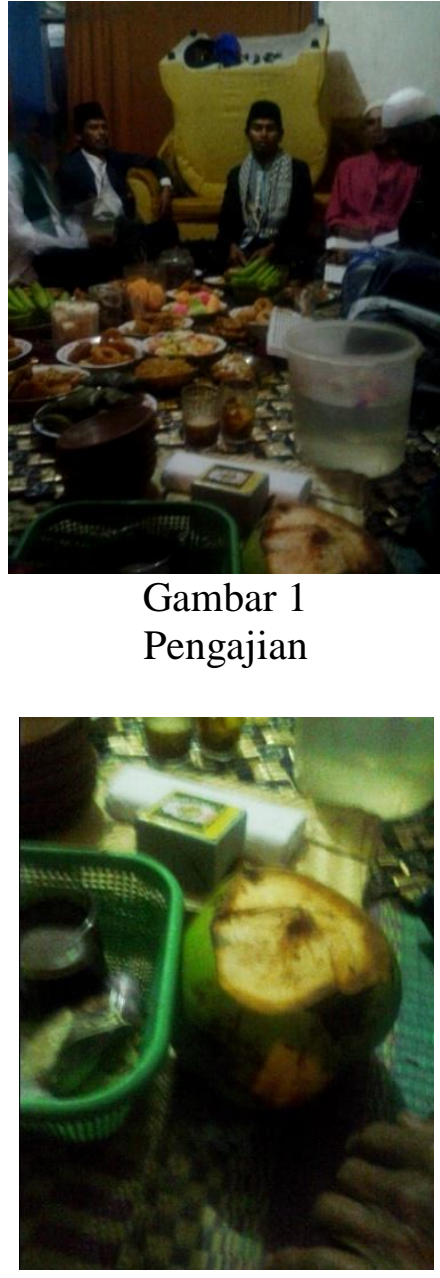

Gambar 2

Syarat-syarat

Besoknya, keluarga biasanya sudah menyiapkan rujak yang nantinya akan dijual oleh yang sedang mengandung. Bahan-bahan untuk rujak biasanya terdiri dari tujuh buah-buahan yaitu, pepaya, ubi, jambu, delima, nanas, belimbing, dan mentimun. Semua buahbuahan tersebut dipotong kecil-kecil yang selanjutnya dicampur dengan bumbu rujak. Setelah semua beres, kemudian rujak tersebut disatukan bersama syarat lain yang telah disediakan seperti,, belut, air kembang, beras dan uang, kanjut kundang atau gonggorekan, bawang putih, jarum dan benang putih, pisau kecil, waluh, kain samping, bedan dan sisir, parupuyan, umbi-umbian, dupi, bongko, wajit ngora dan dodol. 


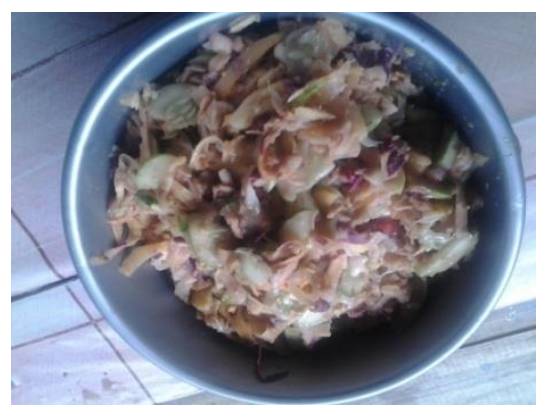

Gambar 3

Rujak tujuh rupa

Setelah semua syarat terkumpul. Selanjutnya paraji menyalakan parupuyan atau sabut kelapa tempat membakar kemenyan untuk meminta doa kepada yang maha kuasa serta kepada Aki Paraji Sakti Ahmad Rahmatullah dan Nini Paraji Sakti Nyi Mas Siti Habibah Kusumah. Selanjutnya, paraji mendandani yang sedang mengandung agar terlihat bersinar. Kemudian paraji mengelus-ngelus perut yang sedang mengandung yang sebelumnya diusapkan terlebih dahulu ke buah waluh memakai minyak keletik. Cara ini dimaksudkan agar kandungannya waluya (sehat).

Ibu yang sedang mengandung selanjutnya mengganti baju dengan memakai kain samping, kemudian dibawa keluar atau halaman rumah. Diluar sudah disiapkan air kembang yang didalamnya terdapat belut dan uang, selanjutnya si ibu yang mengandung dimandikan. Cara memandikannya sebanyak tujuh kali, dimulai oleh paraji, orang tua, suaminya kemudian saudara atau tetangga yang hadir. Setiap yang memandikan berganti orang, kain samping yang dipakai pun harus diganti, begitu seterusnya sampai tujuh kali. Air sisa memandikan diguyurkan oleh paraji, kemudian belutnya dimasukan ke perut si ibu yang mengandung selanjutnya disalosorkeun ke dalam perut. Hal ini dimaksudkan agar ketika proses persalinan dapat berjalan lancar, licin seperti belut. Bersamaan dengan paraji yang mengguyurkan air, dawegan harus dibelah menjadi dua oleh suaminya dengan cara dibelah memakai golok.

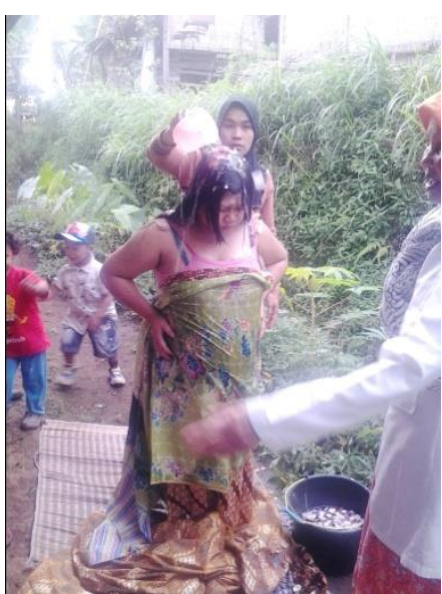

Gambar 4

Mamandikan yang Sedang Hamil

Setelah beres memandikan, si ibu yang sedang mengandung masuk ke dalam rumah dengan menginjak kain samping bekas memandikan tadi. Setelah berganti pakaian, ibu yang sedang mengandung biasanya diperiksa oleh paraji, posisi si bayi dan perkiraan melahirkan, apakah masih lama atau tinggal sebentar lagi. Setelah itu, si ibu yang mengandung kemudian berdagang menjual rujak yang tadi, uang yang biasa dipaki biasanya berbentuk talawengkar atau pecahan genteng yang dibentuk bulat, tapi makin ke sini biasanya memakai uang biasa. Uang hasil penjualan rujak biasanya dimasukan ke dalam kanjut kunang, biasanya dilengkapi dengan panglay, bawang putih, jarum, benang serta pisau kecil.

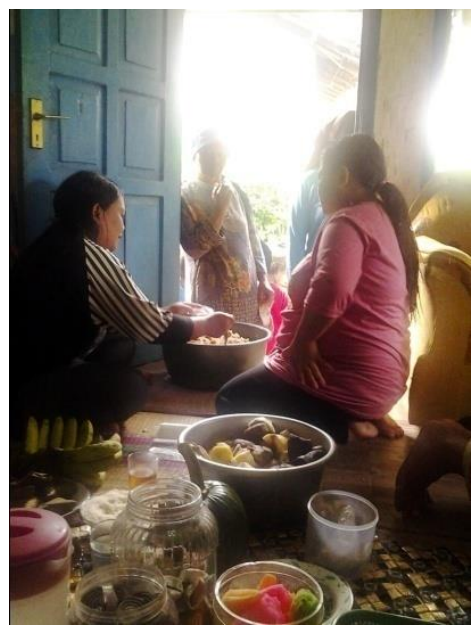

Gambar 5

Berjualan Rujak 
Data yang berupa tata cara pelaksaan, barang-barang, sarat-sarat, serta laranganlarangan dalam nujuh bulanan dianalis berdasarkan jenis folklor. Berdasarkan hasil analisis, terdapat empat jenis folklor lisan, lima jenis folklor sebagian lisan, dan enam belas folklor non lisan. Folklor lisan dalam tradisi nujuh bulanan terdapat dalam larangan-larangan yang tidak boleh dilakukan seseorang yang sedang mengandung, diantaranya tidak boleh melilitkan handuk di kepala dan tidak boleh duduk di depan pintu. Folklor sebagian lisan terdapat dalam kepercayaan-kepercayaan atau takhyul dalam tradisi nujuh bulanan. Contohnya, belut yang disalosorkan ke dalam perut dipercaya agar ketika melahirkan lancar, licin seperti belut. Mengusapkan minyak keletih ke perut yang sebelumnya diusapkan terlebih dahulu ke waluh dipercaya agar kandungannya waluya (baik). Folklor non lisan dalam tradisi nujuh bulanan terdapat dalam syaratsyarat serta makanannya. Diantaranya kain samping, cobek, lentera, kipas, air kembang, belut, dawegan, jarum, benang putih, dan kanjut kundang. Sedangkan dalam makanan terdapat umbi-umbian, seperti singkong, ubi, ganyol, ubi manis, kacang tanah, dan talas. Rujak yang terdiri dari mentimun, ubi, belimbing, nanas, delima, pepaya dan jambu, serta makananmakanan khas lain yang terdapat dalam nujuh bulanan.

Hasil penelitian mengenai folklor dalam tradisi nujuh bulanan di kecamatan cilawu kabupaten garut dapat dijadikan bahan pembelajaran membaca artikel kebudayaan di SMA kelas XII.

\section{SIMPULAN}

Berdasarkan hasil penelitian mengenai analisis folklor dalam tradisi nujuh bulanan di kecamatan cilawu kabupaten garut, dapat disimpulkan seperti dibawah ini.

1) Untuk memperoleh data mengenai folklor dalam tradisi nujuh bulanan, peneliti menggunakan teori folklor
Danandjaja. Dalam penelitian ini menggunakan metode deskriptif kualitatif, yang mempunyai tujuan untuk mendeskripsikan atau menjelaskan tata cara pelaksanaan dalam tradisi nujuh bulanan dan folklor yang terdapat dalam tradisi tersebut.

2) Dalam tata cara pelaksaan tradisi nujuh bulanan terdapat tiga kebiasaan, yaitu pengajian yang biasa dilakukan malam sebelum memandikan, selanjutnya besok harinya membuat rujak serta memandikan yang sedang mengandung. Dalam pengajian biasanya membacakan suray Mariyam, surat Yusuf, surat Yasin serta Solawat Kamilah. Sarat-sarat dalam tradisi nujuh bulanan yaitu, tujuh kain samping, kipas, cobek, benang putih, jarum, air kembang, belut, uang, umbi-umbian, hahampangan (makanan ringa/renyah), kanjut kundang beserta isinya, kelapa muda (dawegan), sabut kelapa, sisir, labu, sesajen dan beras.

3) Berdasarkan hasil analisis, terdapat folklor yang dibagi menjadi empat folklor lisan, lima folklor sebagian lisan dan enam belas folklor non lisan.

4) Hasil penelitian dapat dijadikan bahan pembelajaran membaca artikel kebudayaan di SMA kelas XII.

\section{PUSTAKA RUJUKAN}

Arikunto. (2010). Prosedur Penelitian Suatu Pendekatan Praktik. Jakarta: Rineka Cipta

Danandjaja, J. (2007). Folklor Indonesia. Jakarta: PT Pustaka Utama Grafiti.

Mustapa, H.R.H. (1996). Adat Istiadat Sunda. (disunting $\mathrm{ku}$ Maryati Sastrawijaya). Bandung: Alumni.

Yuniawati, T. (2012). Ajen Falsafah dina Upacara Adat Nyangku di Kampung CukangPadung Desa Panjalu Kecamatan Panjalu Kabupatén Ciamis Pikeun Bahan Pangajaran 
Maca Bahasan di SMA kelas XI. Bandung: JPBD UPI.

Chandrarini. (2010). Upacara Tingkeban Nujuh Bulanan. [Online]. Tersedia di http://chandrarini.com/upacaratingkeban-nujuh-bulanan. Diakses 4 Januari 2014
UCAPAN TERIMA KASIH

Terima kasih kepada pengelola jurnal Lokabasa yang telah menerbitkan tulisan ini. Semoga tulisan ini ada manfaatnya bagi perkembangan ilmu pengetahuan. 